\title{
Investigating the foF2 variations at the lonospheric Observatory of Rome during different solar cycles minimums and levels of geomagnetic activity
}

\author{
Alessandro Ippolito ${ }^{1, *}$, Loredana Perrone ${ }^{2}$, Christina Plainaki ${ }^{1}$, and Claudio Cesaroni ${ }^{2}$ \\ ${ }^{1}$ Italian Space Agency, ASI, Via del Politecnico, 00133 Rome, Italy \\ 2 Istituto Nazionale di Geofisica e Vulcanologia, Via di Vigna Murata 605, 00143 Rome, Italy
}

Received 10 May 2019 / Accepted 11 September 2020

\begin{abstract}
The variations of the hourly observations of the critical frequency foF2, recorded at the Ionospheric Observatory of Rome by the AIS-INGV ionosonde (geographic coordinates $41.82^{\circ} \mathrm{N}$, $12.51^{\circ} \mathrm{E}$; geomagnetic coordinates $41.69^{\circ} \mathrm{N}, 93.97^{\circ} \mathrm{E}$ ) during the low activity periods at the turn of solar cycles 21-22, 22-23 and 23-24, are investigated. Deviations of foF 2 greater than $\pm 15 \%$ with respect to a background level, and with a minimum duration of $3 \mathrm{~h}$, are here considered anomalous. The dependence of these foF 2 anomalies on geomagnetic activity has been accurately investigated. Particular attention has been paid to the last deep solar minimum 2007-2009, in comparison with the previous solar cycle minima. The lack of day-time anomalous negative variations in the critical frequency of the F2 layer, is one of the main findings of this work. Moreover, the analysis of the observed foF2 anomalies confirms the existence of two types of positive F2 layer disturbances, characterised by different morphologies and, different underlying physical processes. A detailed analysis of four specific cases allows the definition of possible scenarios for the explanation of the mechanisms behind the generation of the foF 2 anomalies.
\end{abstract}

Keywords: Ionospheric anomalies / foF2 / ionosonde / ionosphere (mid latitude) / space weather

\section{Introduction}

The response of the Earth's ionosphere to geomagnetic storms is an integral part of Space Weather. The related features appear at different ionospheric altitudes depending on the origin, morphology and evolution of the actual geomagnetic storm (Essex, 1979; Fuller-Rowell et al., 1994; Danilov \& Lastovicka, 2001; Rodger et al., 1989). From a space weather perspective, the associated effects regard, in general, either the mid-latitude ionosphere (in particular, the F2 or the F1-E region) or the low latitude ionosphere (Huang et al., 2005; Bremer et al., 2009). Monitoring and forecasting of space weather effects in the ionosphere has as necessary requisites the in depth understanding of the coupling mechanisms appearing during a geomagnetic storm and the related dynamics (e.g. event evolution and time scale). The current paper is focused on the study of F2 layer disturbances, including ionospheric storms, which are strong manifestations of space weather. The response of the F2 region to a geomagnetic storm depends on the onset time of the latter, season, solar activity and latitude (Basu et al., 1975; Prölss, 1995, Buonsanto, 1999; Alfonsi et al., 2001; Kil et al., 2003;

\footnotetext{
*Corresponding author: alessandro.ippolito@est.asi.it
}

Danilov, 2013). A morphology of the disturbed F2 layer is considered in terms of negative and positive phases, which means a decrease or an enhancement of the maximum electron concentration in the F2 layer, with respect to a background value. The different phases of foF 2 disturbances, are produced by physical mechanisms directly related to global thermospheric circulation, neutral composition and temperature, electric fields, and plasmaspheric flux changes (Rishbeth, 1991; Prölss, 1995). Generally speaking, the number of positive storms effects is expected to be greater in winter months and equinoxes, with a minimum in the summer season. An opposite behaviour is observed for negative storms effects (Obayashi, 1964; Zevakina, 1971; Matuura, 1972; Mendillo \& Klobuchar, 1975; Wrenn et al., 1987; Mikhailov \& Perrone, 2014). Morphological studies suggest that positive storms effects occur in any local time (LT) sector, while negative storms effects are more frequently detected in the post-midnight/early-morning LT sector (e.g. Tsagouri \& Belehaki, 2008, Mikhailov et al., 2012). This because the energy input at high latitudes can produce changes in thermospheric wind composition, resulting in significant variations of the ionospheric electron density (Mikhailov \& Perrone, 2009). Day-time positive storms effects are typically associated with weak or moderate geomagnetic disturbances 
(Zevakina \& Kiseleva, 1978; David \& Sojka, 2010), which may be related to an increasing of auroral activity. Nevertheless, daytime strong positive variations in the ionospheric electron density, may also occur under quiet geomagnetic conditions (Mikhailov et al., 2004, 2007). The main cause of mid-latitude day-time positive variation in the foF2, are equatorward winds associated with Travelling Atmospheric Disturbances (TAD) (Bauske and Prölss, 1997, 1998). Such disturbances induce changes in global thermospheric circulation, increasing of $\mathrm{O} /$ $\mathrm{N}_{2}$ ratio and electric field penetration (Evans, 1973; Prölss 1991, 1995; Mikhailov et al., 1995; Lu et al., 2008; Paznukhov et al., 2009; Balan et al., 2010). Night-time positive enhancements in the critical frequency of the F2 layer may be related to plasma influx from the plasmasphere into the night-side F2 region. For low latitude ionospheric stations, it has been proposed that the night-time foF 2 positive variations, are most likely due to poleward extension of the equatorial ionization anomaly (Rishbeth et al., 2010). However, this is not the case for mid latitudes ionospheric stations, such as the Ionospheric Observatory of Rome, where the increasing in the foF2 observed during night-time, could be the result of plasmaspheric plasma influx, probably due to an electric field originated in the magnetosphere, that drives the plasma from the higher shell to the lower shell. Zevakina \& Kiseleva (1978) revealed two different types of positive ionospheric storms: Type I is referred to those disturbances followed by quiet ionospheric conditions. Positive disturbances of Type II are followed by a negative phase in the foF 2 trend, in this case, the positive and the negative phase constitute different part of a single Type II storm. This classification is of significant importance in the context of space weather since the related types of disturbances generated by different mechanisms, determine a different impact on the ionosphere. In general, the investigation of the mid-latitude ionosphere is complex. This is due to the numerous comparable processes taking place during geomagnetic storms; photo-production, chemical loss, transport by thermal expansion, neutral winds, waves, tides and electric fields of internal and external origin are some of the ongoing ionospheric processes (Mendillo \& Narvaez, 2009). The ionospheric storm effects resulting from a geomagnetic storm, differ considerably from storm to storm (Danilov, 2013) hence, in the context of future space weather applications of forecasting and nowcasting, knowledge on the both past-events and related underlying processes becomes particularly important. In this view, in the current paper we aim:

- to conduct a statistical analysis of ionospheric anomalies observed by the Rome ionosonde during years of low solar activity, considering the last three solar cycles;

- to examine the differences between the deep solar minimum 2007-2009, with respect to the minima of the previous two solar cycles;

- to provide a morphological analysis of positive and negative storm effects observed at mid latitude;

- to investigate Type I and Type II disturbances cases, describing the possible physical mechanisms.

Our results, presented in Sections 3 and 4, can find several applications in the field of Space Weather. First, they provide important scientific information (e.g. foF2 trend, TEC evolution) for understanding the physical mechanisms underlying ionospheric storms which, subsequently, allow the definition of more accurate models of space weather monitoring. Second, they can be further used either as a feedback for the improvement of current space weather monitoring models or as test cases for existing codes for the identification and forecasting of ionospheric parameters (see for example, Stanisławska \& Zbyszynski, 2001; Grozov et al., 2018).

\section{Materials and method}

A characterization of mid latitude ionospheric disturbances is presented, considering the frequency foF 2 , following the preliminary study conducted by Ippolito (2019). Manually scaled validated data of foF2, coming from vertical ionograms recorded by the AIS-INGV ionosonde, at the Ionospheric Observatory of Rome (Latitude 41.8 N, Longitude 012.5 E), have been studied, for the years 1985, 1986, 1987, 1995, 1996, 1997, 2007, 2008 and 2009. These data have been acquired on the INGV-eSWua web portal (http://www.eswua. ingv.it), where automatically scaled ionospheric parameters, are also available for downloading (Scotto \& Pezzopane, 2002; Cesaroni et al., 2013; Ippolito et al., 2015, 2016, 2018). In the purpose to spot any possible anomaly in the critical frequency of the F2 layer, we computed a background value, considering a 27-days running median for the foF2 (Kutiev \& Muhtarov, 2001). The deviations $\delta f$ of foF 2 hourly values from the background, is the parameter we used to define the occurrence of an anomaly in the frequency foF 2 .

$$
\delta f=\frac{f_{\text {(hourly) }}-f_{\text {(background) }}}{f_{\text {(background) }}} .
$$

The variation in percentage is obtained multiplying $\delta f$ by a factor 100 . Variations characterised by percentage of $\delta f \geq 15 \%$, were here considered as anomalies (Mikhailov et al., 2012). For each one of the identified foF 2 anomalies, the study of the related geomagnetic conditions considering the $a_{p}$ geomagnetic index and the $A E$ auroral electrojet index, provided a characterization of the observed ionospheric disturbances. The mentioned geomagnetic indices have been selected because of their capability to define quiet and disturbed periods, in association with the observed ionospheric strong variations (Perrone \& De Franceschi, 1998). The 3-h $a_{p}$ values recorded in the $24 \mathrm{~h}$ preceding the detected anomaly, have been taken into account. We considered the class of the maximum value among the $8 a_{p}$ values corresponding to the considered $24 \mathrm{~h}$. A classification of the foF 2 anomalies has been provided, according to the level of disturbances in the geomagnetic field, from G0 to G5, defined for the $a_{p}$ index by the National Oceanic and Atmospheric Administration (NOAA) (ftp://ftp.ngdc.noaa.gov/STP/ GEOMAGNETIC_DATA/INDICES/KP_AP). The classification levels for the geomagnetic disturbances, go from "quiet conditions", described by $a_{p}$ within 0 and 32, which corresponds to the G0 class, to "extreme storm conditions", where $a_{p}$ reaches value 400 and it is classified in the G5 class.

\section{Data analysis and results}

All the foF2 anomalies have been catalogued according to the geomagnetic activity level as defined by the classes of the 
Table 1. Number of foF2 anomalies, with duration greater than $3 \mathrm{~h}$, classified with respect to the corresponding geomagnetic activity level, together with the yearly values of the F10.7 solar index, the $a_{p}$ geomagnetic index and the number of foF 2 anomalies with a minimum duration of $1 \mathrm{~h}$.

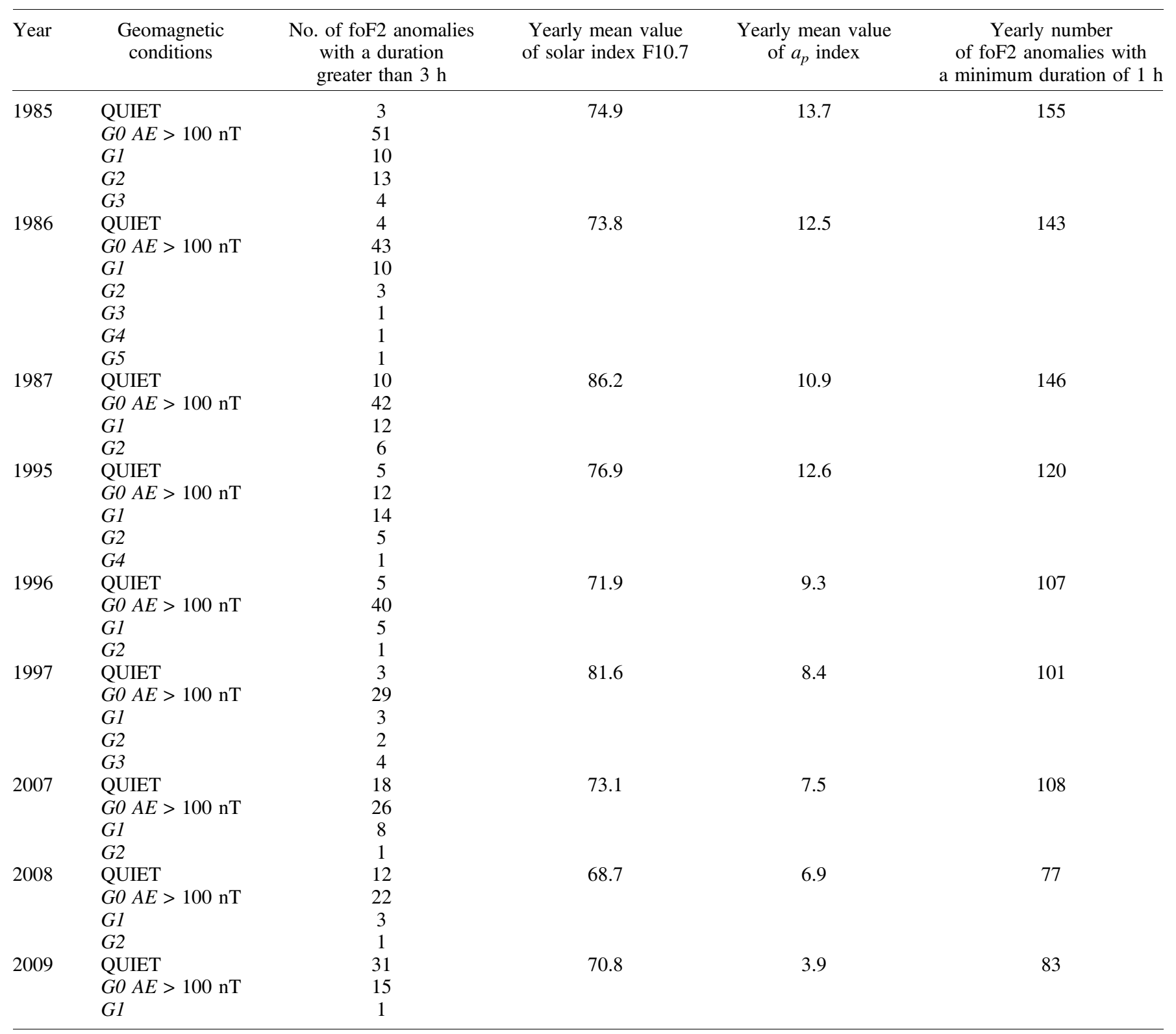

$a_{p}$ index. For the anomalies observed during quiet geomagnetic activity ( $G O$ level), the auroral electrojet index $A E$, has also been studied. The $A E$ values, for a window of $6 \mathrm{~h}$ before the occurrence of the detected anomaly, has been taken into account, in order to consider also the possible neutral winds effect on the ionospheric layers (Prölss, 1993; Buonsanto \& Witasse, 1999). Indeed, Joule heating, produced by the convection electric field and energetic particles precipitation, contributes to increase the thermosphere temperature at high latitudes. This induces an intensification of the equatorward winds and the formation of Travelling Atmospheric Disturbances (TAD), which, moving toward low latitudes, are responsible of strong perturbations of the ionospheric F2 layer at mid latitudes. Quiet auroral electrojet activity are typically characterised by
$A E$ values lower than $100 \mathrm{nT}$. In this work we defined an additional geomagnetic quiet condition, characterized by an $a_{p}$ index ranging in the 0-32 range and an $A E$ index lower than $100 \mathrm{nT}$. Three-hour $a_{p}$ data are provided by NOAA, and are free for download at the web page ftp://ftp.ngdc.noaa.gov/STP/ GEOMAGNETIC_DATA/INDICES/KP_AP. The hourly $A E$ index data are retrieved through the Kyoto $A E$ index service at the web page http://wdc.kugi.kyoto-u.ac.jp/dstae/index.html. During the years of minimum solar activity, at the turn of solar cycles 21-22, 22-23, 23-24, a total number of 1040 anomalies of the critical frequency of the F2 layer have been identified. In Table 1 we report, for each analysed year, the total number of the observed foF 2 anomalies (with a duration of at least of $1 \mathrm{~h}$ ) together with the corresponding yearly average values of 
Total number of foF2 anomalies per year

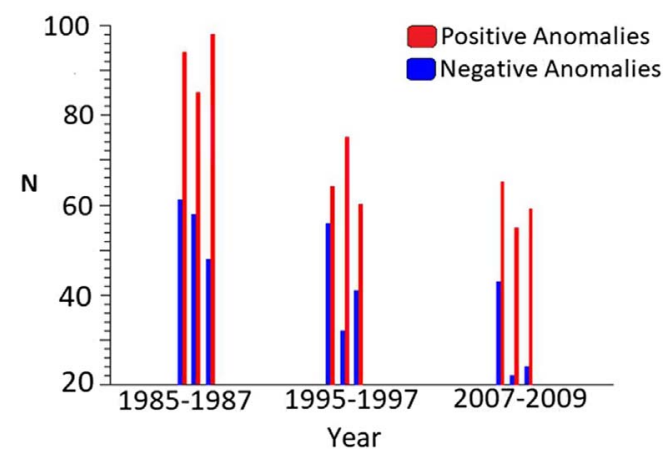

Fig. 1. Total number of positive and negative foF 2 anomalies, with a minimum duration of $1 \mathrm{~h}$, observed per year at the Rome observatory.

the solar index F10.7 and the geomagnetic index $a_{p}$, computed as a mean of the monthly values of the two indexes. Hourly values of the solar index F10.7 have been used, provided by Space Physics Data Facility (SPDF) of the NASA Goddard Space Flight Center, through the Omniweb data explorer service (https://omniweb.gsfc.nasa.gov/form/dx1.html).

Figure 1 presents the total number of positive and negative foF2 anomalies observed per year. Since solar cycle minima are considered in this work, no particularly high solar flux F10.7 is observed, although, looking at the yearly mean values reported in Table 1 and plotted in Figure 2a, it can be seen an agreement between the total number of the observed foF2 anomalies, with a minimum duration of $1 \mathrm{~h}$ reported in Figure 1, and the intensity of the solar flux. Indeed, the greater number of anomalies are observed during the years 1985-1987, characterised by a more intense solar flux, compared with the other analysed years, while the lowest number of foF 2 anomalies is observed during the minimum of 2007-2009, where the lowest solar flux is recorded.

The same agreement seems to be clear between the number of foF 2 anomalies, with a minimum duration of $1 \mathrm{~h}$, and the geomagnetic conditions, described by the yearly mean values of $a_{p}$ index reported in Table 1 and Figure 2b. Our results confirm that the occurrence of the foF2 anomalies depends on both the solar and the geomagnetic activity. Indeed, the minimum number of foF2 anomalies is recorded in 2008 and 2009. The lowest occurrence of anomalies is observed in 2008, when the yearly F10.7 value is minimum and the $a_{p}$ index has low values. Besides, the greatest number of ionospheric anomalies, are observed in 1985, when the yearly mean value of $a_{p}$ index reaches its maximum for the analysed years, equal to 13.7. The 1985-1987 solar minimum is characterised by more intense solar and geomagnetic activities with respect to the other minima studied in this work. Indeed, the number of foF2 anomalies found for the 1985-1987 periods is greater than the number of anomalies observed during the other solar cycle minima. Instead, in the last analysed minimum, 2007-2009, the observed number of foF 2 anomalies is relatively low, whereas at the same time the number of the positive anomalies is considerably larger than the number of negative ones. According to the data presented in Table 1, we argue that this remarkable situation is directly connected to the low solar and geomagnetic activity, as confirmed also by the results showed by Buresova et al. (2014). In the following we mainly focused our attention on disturbances in the critical frequency of the F2 layer, that last for at least $3 \mathrm{~h}$, and so considered as ionospheric perturbations. In Table 1 we report, for each analysed year, the number of foF 2 anomalies, with a duration greater than $3 \mathrm{~h}$, classified with respect to the corresponding geomagnetic activity level. In the panels of Figure 3, we report the percentages of anomalies in relation with the geomagnetic conditions, for the year of solar minimum analysed. The percentage is computed considering, for the whole year, the total number of days characterised by that particular geomagnetic level. The total number of positive and negative anomalies, respectively in red and blue in Figure 3, occurred during the analysed year, and observed during a particular geomagnetic condition, has been divided for the number of days, for which that geomagnetic condition, was recorded in the year taken into account.

The minima at the turn of solar cycles of 21-22 and the 22-23, are characterised by a comparable number of ionospheric anomalies detected during Quiet conditions. Looking at the anomalies percentages in Figure 3, we note that the ionospheric anomalies percentages increase in 1987, 1995 and 1996. This is because, in these years, we found less data related to geomagnetic condition $a_{p}=\mathrm{G} 0$ and $A E<100 \mathrm{nT}$. The anomalies found in the years 1985, 1986, 1987, 1995, 1997 in level G1 and level G2, are comparable in number and percentage, this reflects the disturbed geomagnetic conditions observed during these years, mostly characterised by $a_{p}=\mathrm{G} 1$ and $a_{p}=\mathrm{G} 2$. Concerning the years at the turn of solar cycles 23-24, we found a greater number of foF2 anomalies observed during quiet geomagnetic conditions, with respect to the previous years, this is probably due to the higher number of days characterised by geomagnetic condition $a_{p}=\mathrm{G} 0$ and $A E<100 \mathrm{nT}$. Indeed, because of the deep solar minimum recorded at the turn of solar cycles 23-24, the geomagnetic activity as described by the $a_{p}$ index, reaches at most the G2 level. In Table 2, for each analysed year, is reported the percentage of positive and negative foF 2 anomalies, with a duration of at least $3 \mathrm{~h}$, computed over the total number of the foF 2 anomalies observed during nighttime hours and day-time hours, respectively.

In this work, we consider November, December, January and February as winter season; March, April, September and October as equinox season; May, June, July and August as summer season. It can be seen that negative disturbances are more often observed during night-time, and during summer months and equinoxes. On the other hand, in the same periods of the year, positive disturbances are detected especially during day-time. For day-time we consider the hours within 08:00 and 14:00 LT, while hours within 22:00 and 03:00 LT are considered night-time hours.

When studying the deep solar minimum of 2007-2009, because of a very low solar and geomagnetic activity, the percentage of negative disturbances during daytime is zero.

\section{Analysis of foF2 storm case studies}

Among the foF 2 anomalies observed by the Rome ionospheric station, during the last three solar cycle minima, we 

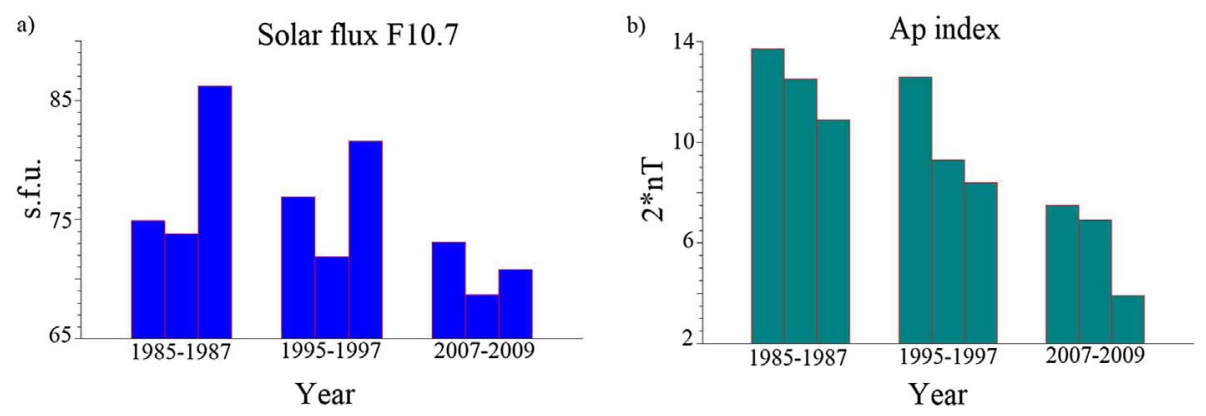

Fig. 2. In panel (a) is reported the yearly average value of the solar flux F10.7, for the considered years of minimum of cycles 21,22 and 23 . Panel (b) shows yearly average value of $a_{p}$ index, for the same years.

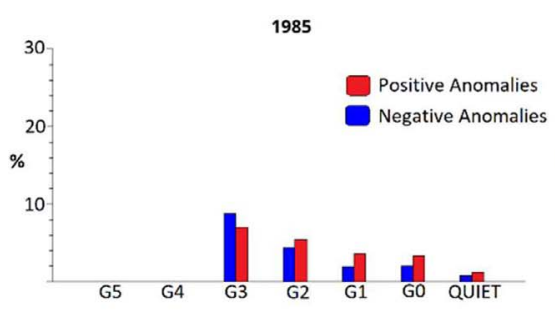

Geomagnetic Conditions

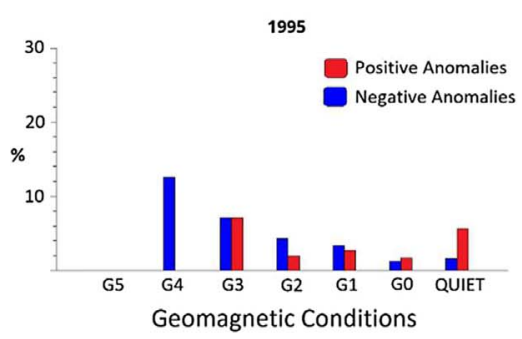

2007

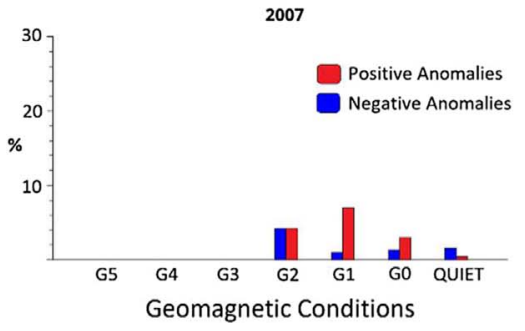

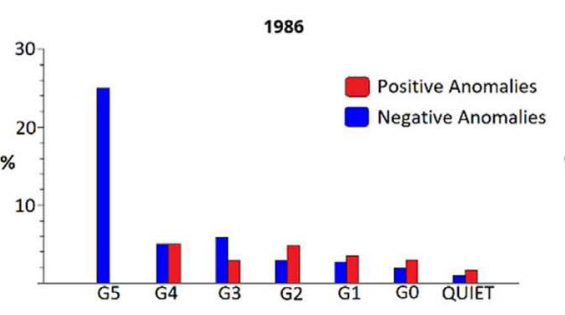

Geomagnetic Conditions
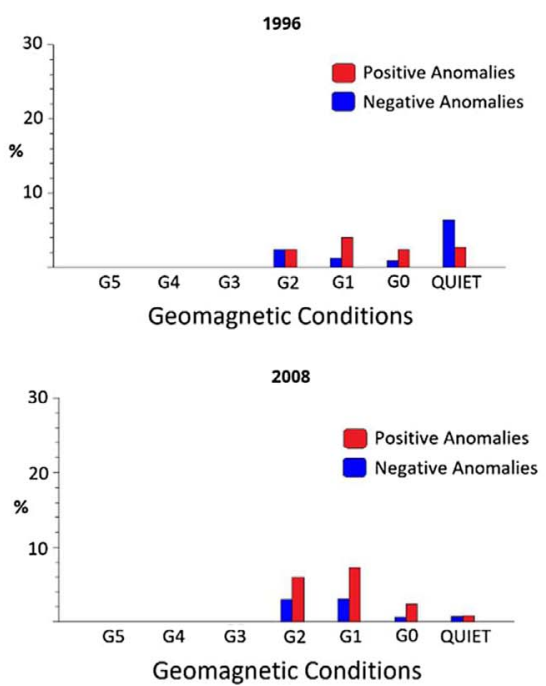

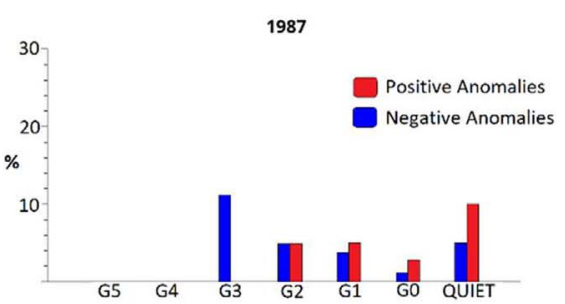

Gesmagnetic (s)nditions
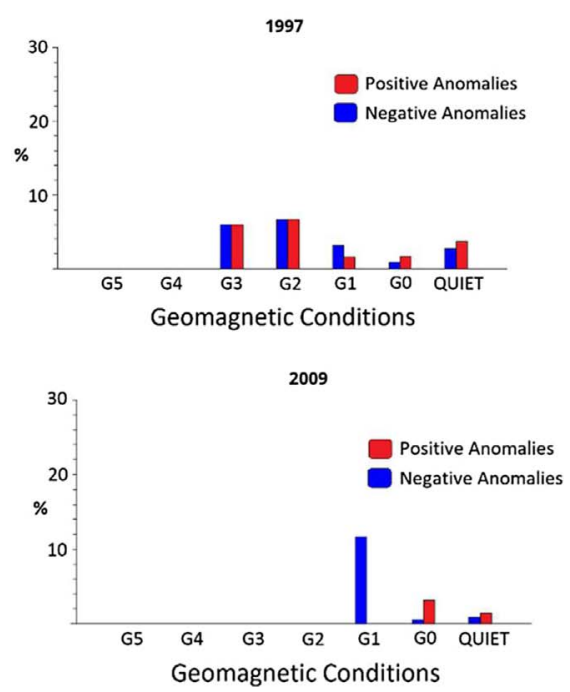

Fig. 3. In the panels are reported the percentages of both positive and negative foF 2 anomalies, for the analysed years of the turn of solar cycles 21-22, 22-23 and 23-24.

investigated the occurrence of strong ionospheric perturbations. In this paper, the strong positive enhancements in the critical frequency of the F2 layer are considered as Type I ionospheric storm, whenever the deviation of the foF2 hourly value with respect to the 27 days running median, is greater than $20 \%$, with a persistence of at least $6 \mathrm{~h}$, followed by quiet foF 2 conditions. A strong positive variation, with a persistence of at least $3 \mathrm{~h}$, preceding a deep decreasing of the foF $2(<-22 \%$ with respect to the 27 days running median), is here considered as Type II ionospheric storm. In Table 3, we report the percentage of Type I and Type II ionospheric storms, related to enhanced geomagnetic activity, and observed during the low solar activity periods at the turn of solar cycles 21-22, 22-23 and 23-24. The percentages have been computed over the total number of foF2 anomalies observed per year.

Table 3 shows that the maximum percentage of Type $I$ ionospheric storms is recorded in 1995 while the minimum percentage is found in 1986. Concerning Type II disturbances, the maximum percentage is found in 1986 due to the higher geomagnetic activity. For the case studies here presented, manually scaled foF 2 hourly values, provided by Juliusruh ionospheric station, have also been considered. Such data are provided by the Australian Space Weather Services data archive (http://www.sws.bom.gov.au/World_Data_Centre/1/3). Besides, 
Table 2. Percentages of positive and negative foF 2 anomalies, with a minimum duration of $3 \mathrm{~h}$, observed by the Rome ionospheric station, computed over the total number of foF 2 anomalies observed during night-time hours and day-time hours respectively.

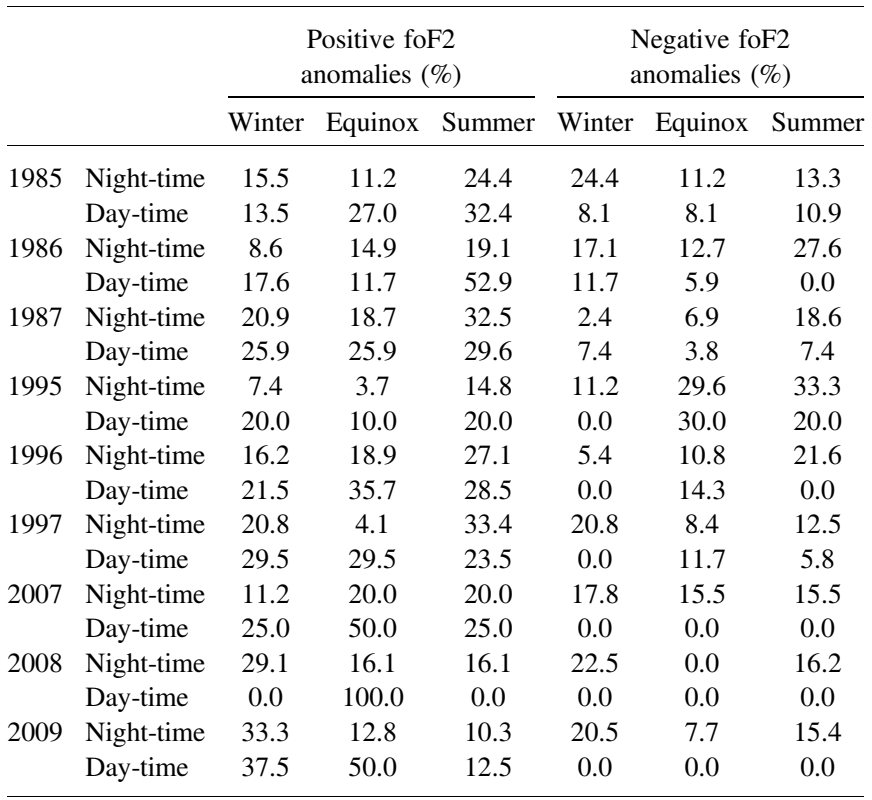

Table 3. Percentage of Type I ionospheric storms and Type II ionospheric storms observed by the AIS-INGV ionosonde at the Ionospheric Observatory of Rome during the minimum of solar activity at the turn of solar cycles 21-22, 22-23 and 23-24.

\begin{tabular}{ccc}
\hline Year & $\begin{array}{c}\text { Percentage } \\
\text { of Type I storms }\end{array}$ & $\begin{array}{c}\text { Percentage of Type II } \\
\text { storms }(\%)\end{array}$ \\
\hline 1985 & $3.9 \%$ & 5.2 \\
1986 & $1.4 \%$ & 13.3 \\
1987 & 8.9 & 10.3 \\
1995 & 8.3 & 0.0 \\
1996 & 3.7 & 2.8 \\
1997 & 6.9 & 9.9 \\
2007 & 4.6 & 1.8 \\
2008 & 5.2 & 7.8 \\
2009 & 3.6 & 0.0 \\
\hline
\end{tabular}

hourly values of IMF magnitude, and IMF Bz component, retrieved from the NASA Omniweb database (https:// omniweb.gsfc.nasa.gov/form/dx1.html), have been analysed for each presented ionospheric storm.

\subsection{The 13th July 1985 Type II ionospheric storm}

A strong Type II foF2 storm has been observed by the AIS-INGV ionosonde of the Ionospheric Observatory of Rome on 13th July 1985 starting at 13 UT (14 LT). For the analysed period strong disturbances in the geomagnetic field are recorded, as reported in Figure $4 \mathrm{~b}$. Indeed, the high values of the $a_{p}$ index, classified in the $\mathrm{G} 3$ category of geomagnetic disturbances, together with the decreasing in the Dst index, describe very perturbed geomagnetic conditions, especially the day before the considered ionospheric storm. The variation of the hourly values of the critical frequency foF 2 (red line) with respect to the background (green line) is presented in Figure 5b. We note that the initial phase of the strong ionospheric disturbance, characterised by a strong enhancement in the foF 2 , is followed by a remarkable decreasing of the ionospheric parameter foF 2 . The same trend is clearly visible in Figure 5a, where foF2 data recorded at the Juliusruh ionospheric station $\left(54.6^{\circ} \mathrm{N}\right.$, $\left.13.4^{\circ} \mathrm{E}\right)$ are reported. The lower panel of the same figure represents the percentage variation of the foF 2 observed by the two ionospheric stations, with respect to the background values. The splash of auroral activity is evident in the $A E$ data which have values up to $1000 \mathrm{nT}$ on 12 and 13 July 1985 (DoY192-193), as can be seen from Figure 4a; coherently to this situation, TAD are expected to be produced. A further analysis of the solar activity in the days preceding the storm, shows an increase in the solar flux F10.7 index, as reported in Figure $4 \mathrm{a}$, therefore, we conclude that conditions of more intense solar activity were present the day before the observed ionospheric storm. Furthermore, values for IMF-B magnitude exceeding $13 \mathrm{nT}$ and a long lasting southward turning of $B z$ are observed for the analysed period. Such variations are typically related to geomagnetic storm occurrence (Tsurutani \& Gonzalez, 1995), which, in this case, directly induce the strong variations in the critical frequency of the $\mathrm{F} 2$ region recorded. The TAD, induced by the strong auroral activity, first arrives at Juliusruh latitude, where the positive phase of the storm is recorded starting from $11 \mathrm{UT}$; then it is observed at the Ionospheric observatory of Rome, with a delay of a couple of hours. The blue vertical lines in the plots of panels a) and b) of Figure 5, represent the onset of the strong positive phase of the ionospheric storm recorded in the two observatories. In both the ionospheric stations, a negative phase of the storm is observed on 14th July (DoY 194), characterised by a sensitive decreasing in the foF2 values, which last for many hours (almost all day). After the negative phase, a recovery phase starts from the first hours of 15th July (DoY 195).

\subsection{The 7 November 1997 Type II ionospheric storm.}

From the Dst values plotted in Figure 6b, it can be seen a perturbed geomagnetic condition, which persists for several days. This evident geomagnetic activity is probably the cause of different ionospheric disturbances which, following one another, are recorded from the two ionospheric stations. Instead of a single storm event, we can see in this case a "train" of ionospheric disturbances, with a peak in the strong ionospheric storm recorded 7th November 1997. Such long-last ionospheric disturbed conditions can be considered as an example of mixed ionospheric response: effects of different types are taking place successively for the same location. A strong positive phase, with a duration greater than $3 \mathrm{~h}$, of a type II ionospheric storm, has been detected by the AIS-INGV ionosonde of the Ionospheric Observatory of Rome, starting on 7th November 1997 (DoY 311). In Figure 7 is reported the enhancement of measured foF2, expressed by its deviation from the background level, measured both by Juliusruh and Rome ionospheric observatories. As showed in Figure 7c, an increasing greater than $50 \%$ is observed during the first phase of the storm. Looking at the auroral electrojet index $A E$, it can be clearly seen an increasing in the auroral activity starting from the 6th November 1997 (DoY 310), characterised by $A E$ up to 
(a)

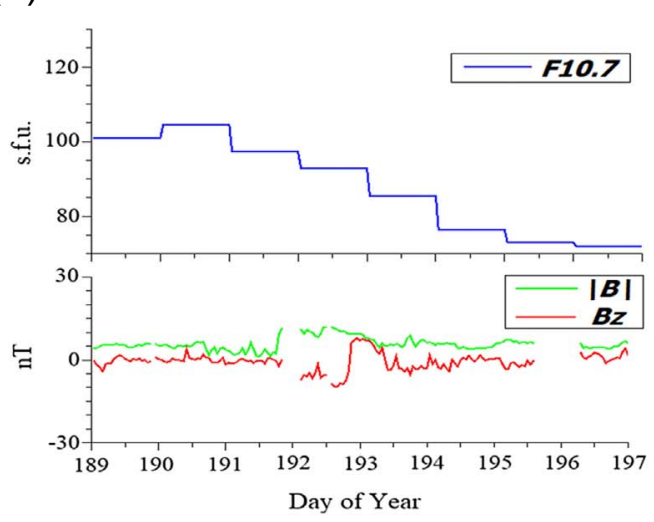

(b)
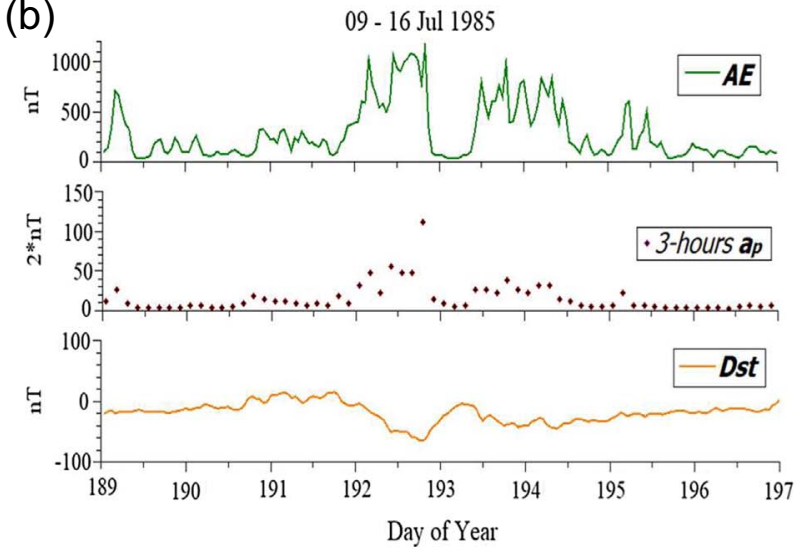

Fig. 4. In panel (a), from up to down, are reported the Solar flux F10.7 from 09 to 16 July 1985 , and the IMF magnitude and $Z$ component evolution for the same period. In panel (b), from up to down, are described respectively the $A E$ index, the $a_{p}$ index and the Dst index, from 09 to 16 July 1985. (The hourly $A E$ index data are retrieved through the Kyoto $A E$ index service http://wdc.kugi.kyoto-u.ac.jp/dstae/index.html. Three-hour $a_{p}$ data are provided by NOAA ftp://ftp.ngdc.noaa.gov/STP/GEOMAGNETIC_DATA/INDICES/KP_AP. Dst and Solar data are obtained from NASA Goddard Space Physics Data Facilities OMNIWEB: https://omniweb.gsfc.nasa.gov/form/dx1.html).

$500 \mathrm{nT}$, so sensibly higher than quiet condition values $(<100$ nT), and reaching a peak of 992 nT on 07 November 1997 (DoY 311). Also the solar index F10.7, has values greater than 100 s.f.u. on 06 November 1997, before a decreasing to lower values in the next days. Because of the joule heating produced in the high latitude atmosphere, and described by these indexes, a TAD has probably been produced. Such a perturbation can be the reason of the increasing in the critical frequency of the F2 layer during day time hours, measured by the ionospheric stations of Juliusruh and Rome (Prölss \& Jung, 1978; Bauske \& Prölss, 1997). foF2 data observed by the two observatories, show an enhancement in Juliusruh on the 6th of November (DoY 310) at 13:00 UT, while in Rome, a strong positive phase is observed starting from mid-day hours of November the 7th (DoY 311). A second phase of the foF 2 storm is described by the decreasing in the critical frequency of the F2 layer recorded on 8th November 1997 (DoY 312). This behaviour is represented also by the plots in Figure $7 \mathrm{~b}$, where the red line represents the trend of the hourly values of foF2, recorded by the Rome observatory, while the green line is the hourly running median. Even if in Juliusruh a positive enhancement in the foF 2 is observed the days before the considered storm, the strongest variation in the critical frequency of the F2 layer is due to the considered Type II storm. Indeed a strong positive deviation is followed by a deep decreasing in the foF2 starting from DoY 311. The same behaviour is observed at Rome latitude, though less evident.

A recovery phase characterised by small variation of foF2 with respect to the background level, is observed starting during the first half of 9th November 1997 (DoY 314), when the ionosphere reaches a quiet status. The increasing in the foF2 values recorded at Rome, corresponds to a sudden enhancement of the geomagnetic index $a_{p}$, as well as to a deep drop in the Dst index, as reported in the plot in Figure 6b. In the same panel, a strong geomagnetic disturbance in action, is also highlighted by a remarkable auroral activity as it can be deduced by the $A E$ index. Values for $B$ magnitude exceed $15 \mathrm{nT}$ are observed for the analysed period, together with a southward turning of $B z$ with values up to $-15 \mathrm{nT}$, which confirm the storm conditions revealed by the geomagnetic indexes, preceding the ionospheric disturbance recorded by both Juliusruh and Rome observatories. The observed ionospheric storm is strongly connected with the intensification of geomagnetic activity, probably as a consequence of the enhancement of the solar activity reflected by the F10.7 solar flux, and probably related to a strong CME recorded on 6th November 1997, as results from the CACTus CME Catalogue (http://sidc.oma.be/cactus/ catalog/LASCO/2_5_0/1997/11/latestCMEs.html).

\subsection{The 16 December 1987 Type I ionospheric storm}

A Type I ionospheric storm has been observed by the AIS-INGV ionosonde of the ionospheric observatory of Rome, on 16 December 1987 (DoY 350). The study of the geomagnetic conditions at the time when the Type I storm is detected shows a moderate activity (see Fig. 8b). Indeed, the $a_{p}$ index is classified in the $G 2$ level, and a smooth variation in the Dst index is visible. However, the high values of the auroral electrojet index, reveal an intense auroral activity just before the occurrence of the Type I ionospheric storm. A strong enhancement in the critical frequency of the F2 layer starts on 11:00 UT, as can be deduced from Figure 9b, and also showed in the Figure 9c, where the percentage variation of the foF 2 observed by Rome and Juliusruh ionospheric stations is reported. A recovery phase for the considered ionospheric parameter is observed in the next days. As discussed above, this kind of storms differs from the Type II ones since they are characterised only by a strong positive variation in the foF2, followed by a recovery phase, without any particular decreasing in the critical frequency foF2.

Although the lack of data regarding the magnitude and the $Z$ component of the IMF, as can be seen from the lower plot of Figure $8 \mathrm{a}$, does not allow any particular interpretation on the interplanetary conditions, a quite intense solar flux F10.7, for some days over 90 s.f.u, is recorded in the analysed period. These values of the F10.7 solar flux reflects some solar activity beside the disturbed geomagnetic conditions described by the indexes $a_{p}$ and $A E$ in the upper plots of Figure $8 \mathrm{~b}$. 

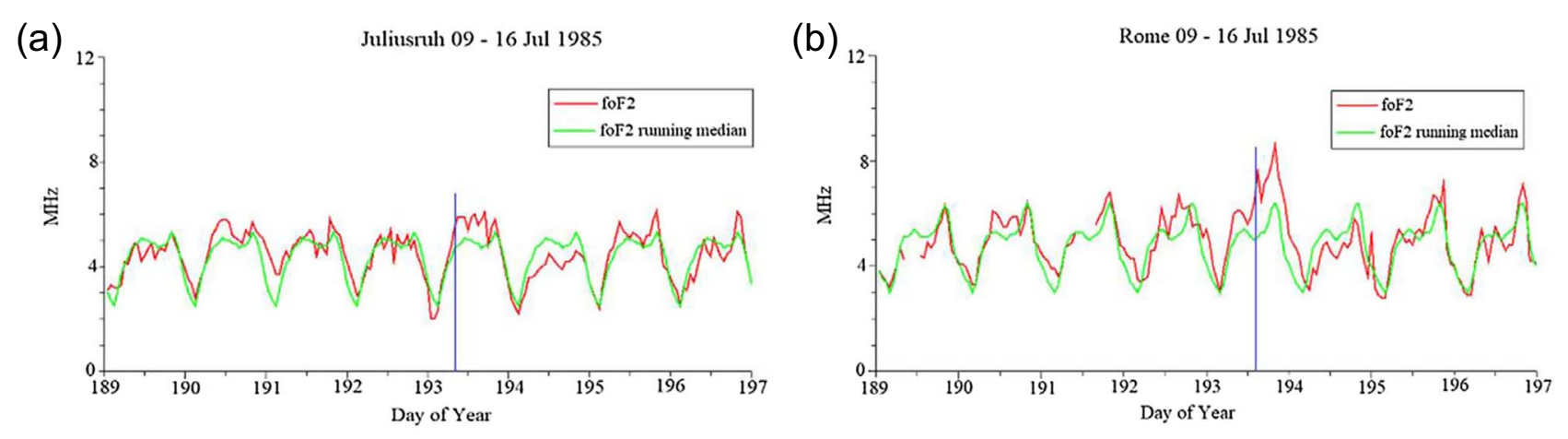

(c)

$09-16$ Jul 1985

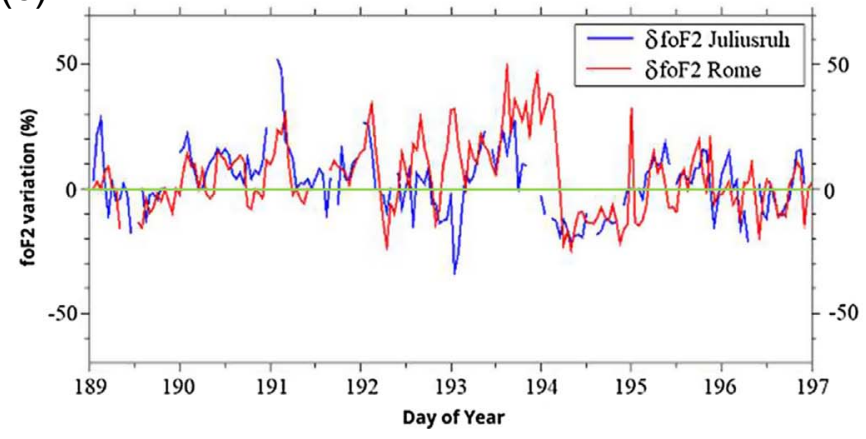

Fig. 5. (a) Hourly values of foF 2 as recorded at Juliusruh ionospheric station from 09 to 16 July 1985 (red line) together the foF 2 running median evolution in the same period (green line). The latter is considered as a background value of the ionospheric parameter. (b) Hourly values of foF 2 as recorded at the Ionospheric Observatory of Rome from 09 to 16 July 1985 (red line) together the foF2 running median evolution in the same period (green line). The blue vertical lines in the plots represent the onset of the strong positive phase of the ionospheric storm recorded in the two observatories. In panel (c) is reported the variation in percentage of the foF 2 for the two ionospheric stations, for the considered period.

The perturbed foF 2 conditions recorded, constitute the ionospheric response to such enhancement in the geomagnetic activity. From Figure 9 can be noticed that, while the Rome ionosonde observes a strong Type I ionospheric storm (Fig. 9b), starting from day-hours and lasting for several hours (until 00:00 UT), in panel (a) of Figure 9 can be seen how, in the same hours, a negative storm is recorded in Juliusruh observatory (see blue vertical line in the upper panel). This is probably due to a transfer of disturbed composition (low $\mathrm{O} / \mathrm{N}_{2}$ ratio) at Juliusruh latitude which determines a negative storm. Such perturbation in the neutral composition with low $\mathrm{O} / \mathrm{N}_{2}$ ratio, probably does not reach mid latitude, that is why no negative effects are observed in Rome, while, for the mid latitude station, the daytime poleward neutral wind determines a positive storm.

\subsection{The 3 October 1996 Type I ionospheric disturbance}

The ionospheric disturbances observed on 3 October 1996 cannot be clearly assigned to any geomagnetic activity effect. Although the $a_{p}$ index is classified in the G0 level and no particular variation in the Dst index is recorded, as showed in Figure $10 \mathrm{~b}$, an intense auroral activity is underway, causing perturbations in the geomagnetic conditions which are responsible of the ionospheric disturbances of the analysed period. The solar activity levels are low, as described in Figure 10a, indeed, the F10.7 solar flux and the IMF magnitude and $Z$ com- ponent, do not present any significant variations. As can be deduced from Figure 11, similar ionospheric disturbances are observed during a period of several days previous and next to the considered event. The strong enhancement in the foF 2 values recorded by the Rome observatory on 3rd October 1996, should be considered, together with the less intense disturbances of the whole analysed period (DoY 275-282) as examples of disturbances occurred under $G 0$ conditions.

The increasing in the foF 2 recorded in Rome and not seen in Juliusruh, could be also related to a plasmasphere plasma influx, since it is observed during night-time when the plasmasphere might be the only source of increased electron concentration in the F2-region. Since the observed enhancement in the foF2 is followed by quite conditions in the analysed ionospheric parameter, it can be compared as Type I ionospheric storm.

\section{Discussion}

Negative storm effects are related to enhanced auroral activity $(A E$ index) and corresponding geomagnetic activity $\left(a_{p}\right.$ index). Such negative anomalies are usually characterised by a two-phase storm effect: a positive phase in the foF 2 trend, followed by a negative one. Joule heating in the auroral regions, due to particles precipitation, produces pressure gradients in the 
(a)

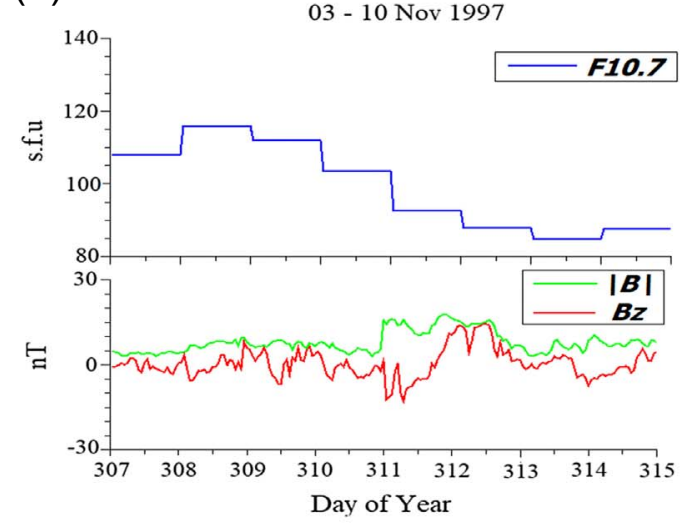

(b)

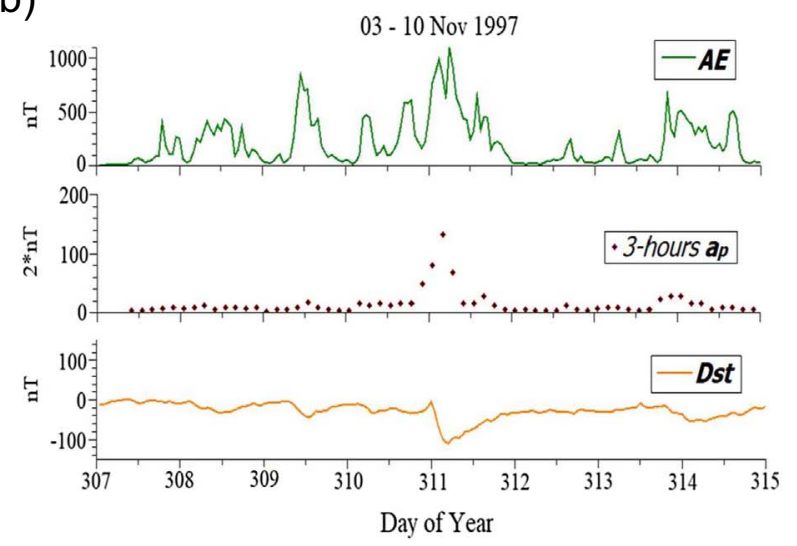

Fig. 6. In panel (a), from up to down, the solar flux F10.7 from 03 to 10 November 1997, and, for the same time period, the behaviour of the magnitude and the $Z$ component of the IMF. Panel (b) shows, from up to down, the $A E$, the $a_{p}$ and the Dst indices, from 03 to 10 November 1997. (The hourly $A E$ index data are retrieved through the Kyoto $A E$ index service http://wdc.kugi.kyoto-u.ac.jp/dstae/index.html. Three-hour $a_{p}$ data are provided by NOAA ftp://ftp.ngdc.noaa.gov/STP/GEOMAGNETIC_DATA/INDICES/KP_AP. Dst and Solar data are obtained from NASA Goddard Space Physics Data Facilities OMNIWEB: https://omniweb.gsfc.nasa.gov/form/dx1.html).

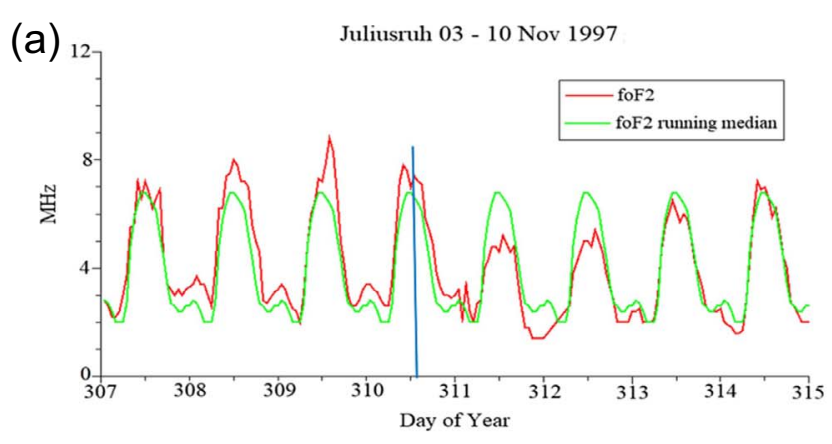

(c) (b)

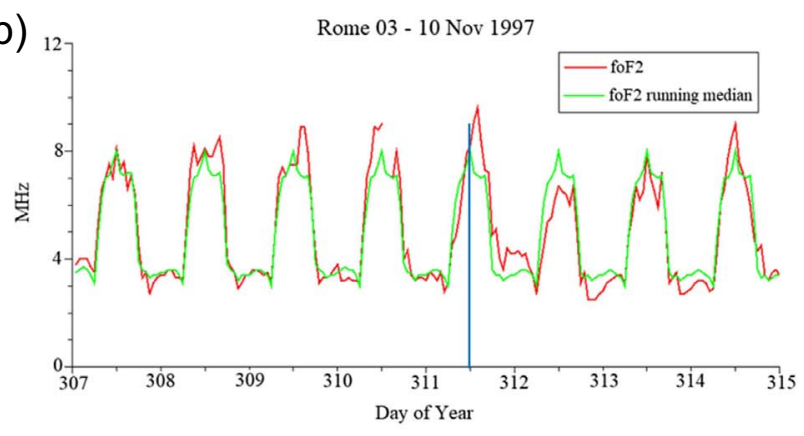

$03-10$ Nov 1997

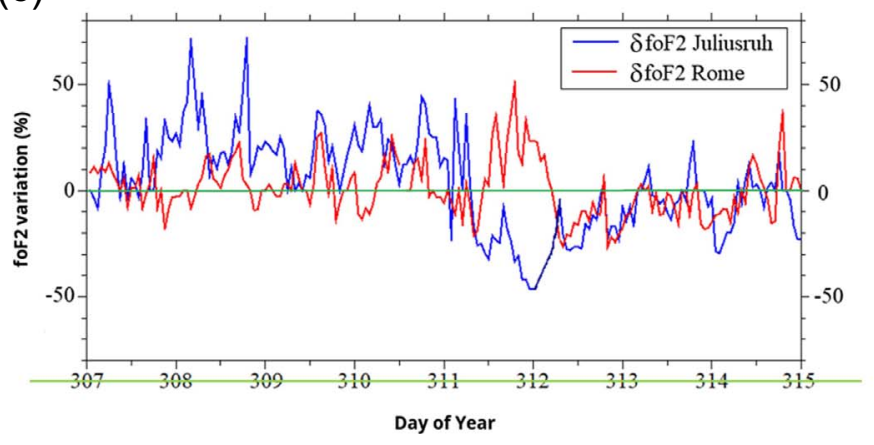

Fig. 7. In panel (a), the red line represents the hourly values of foF2, recorded at Juliusruh ionospheric station from 03 to 10 November 1997 . The green line represents the foF2 running median here considered as background value of the ionospheric parameter. In panel (b) the same parameters, recorded by the Rome ionospheric station, are reported, considering the same time period. In panel (c) is reported the variation in percentage of the foF2 for the two ionospheric stations, for the considered period.

high-latitude ionosphere. As a consequence, equatorward neutral winds reach mid-low latitudes, inducing the positive phase, and altering the ionospheric and thermospheric $\mathrm{O} / \mathrm{N}_{2}$ local ratio (Fang et al., 2012; Yao et al., 2016). Low O/ $\mathrm{N}_{2}$ rates are then responsible for the negative effect on the ionospheric parameter foF2. Our analysis showed that there is a pronounced seasonal dependence in the occurrence of the negative storm-phase. In particular, very few negative foF 2 disturbances, are observed by the Rome ionosonde, during winter season. This is due to the fact that the strong northward thermospheric circulation during winter months, locks the disturbed neutral composition at high latitudes (Prölss, 1995) and, therefore, no modifications 
(a)

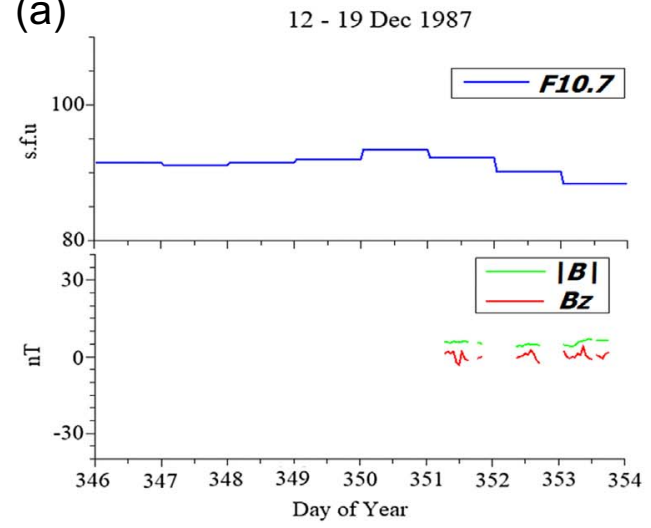

(b)

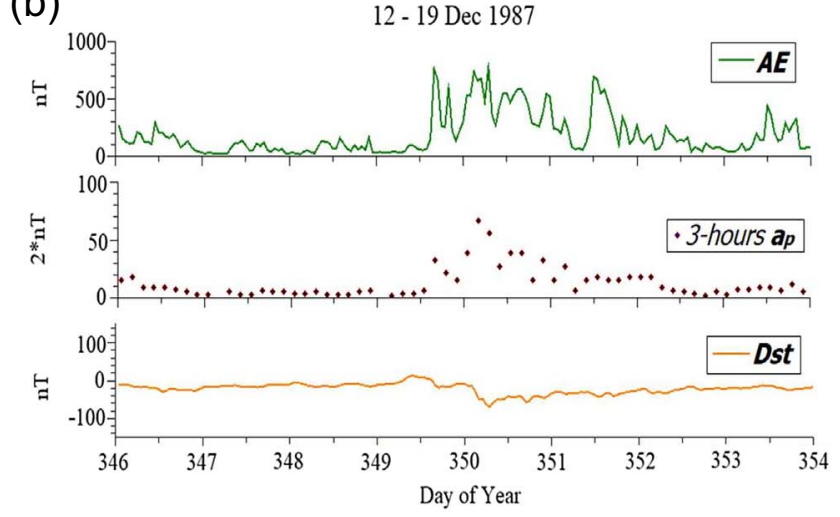

Fig. 8. In panel (a) is described, from up to down, Solar flux F10.7 from 12 to 19 December 1987, and, for the same time period, the behaviour of the magnitude and the $Z$ component of the IMF. Panel (b) shows, from up to down, the $A E$, the $a_{p}$ and the Dst indices, from 12 to 19 December 1987. (The hourly $A E$ index data are retrieved through the Kyoto $A E$ index service http://wdc.kugi.kyoto-u.ac.jp/dstae/index.html. Three-hour $a_{p}$ data are provided by NOAA ftp://ftp.ngdc.noaa.gov/STP/GEOMAGNETIC_DATA/INDICES/KP_AP. Dst and Solar data are obtained from NASA Goddard Space Physics Data Facilities OMNIWEB: https://omniweb.gsfc.nasa.gov/form/dx1.html).
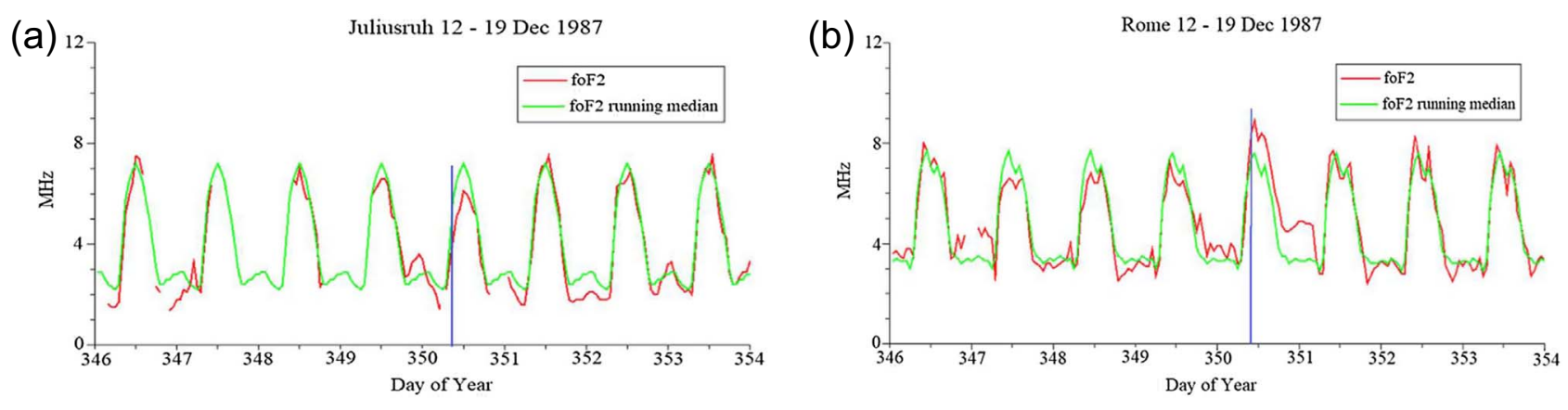

(c)

12 - 19 Dec 1987

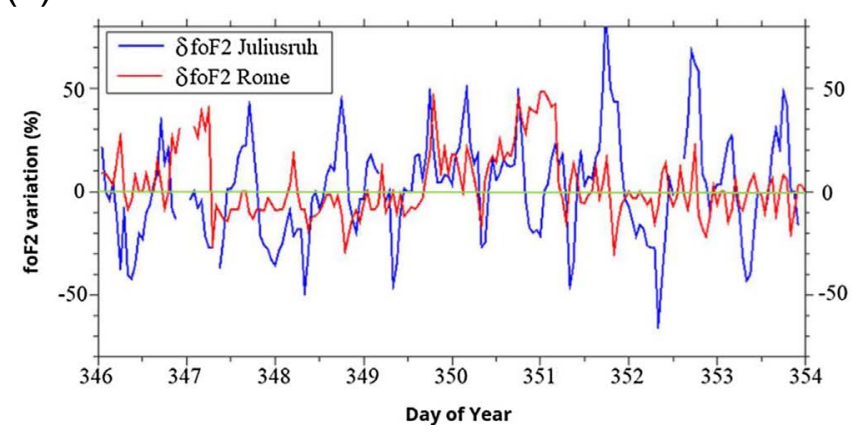

Fig. 9. In panel (a), the red line represents the hourly values of foF2, recorded at Juliusruh ionospheric station from 12 to 19 December 1987. The green line represents the foF2 running median here considered as background value of the ionospheric parameter. In panel (b) the same parameters, recorded by the Rome ionospheric station, are reported, considering the same time period. In panel (c) is reported the variation in percentage of the foF 2 for the two ionospheric stations, for the considered period.

in the $\mathrm{O} / \mathrm{N}_{2}$ ratios can spread to mid latitudes. Instead, during summer months, the thermospheric circulation is pre-eminently equatorward, and the disturbed thermospheric composition is able to reach mid latitudes. Moreover, the possibility that Joule heating and auroral electrojets could have caused the expansion and rise of the neutral atmosphere, resulting in the transferring of $\mathrm{N}_{2}$ molecules from the lower altitudes to higher altitudes causing further decrease of the $\mathrm{O} / \mathrm{N}_{2}$ ratio, should not be excluded. Joule heating, produced by intense particle precipitations at auroral latitude, forces pressure waves to travel through the thermosphere. Such waves, known as Acoustic Gravity Waves (AGW), transfer energy and momentum from high latitudes to low latitudes, and from the lower atmosphere to the upper atmosphere (Karpachev et al., 2010).The positive effect of the foF 2 storm at Rome latitudes during night-time hours, may result from: 

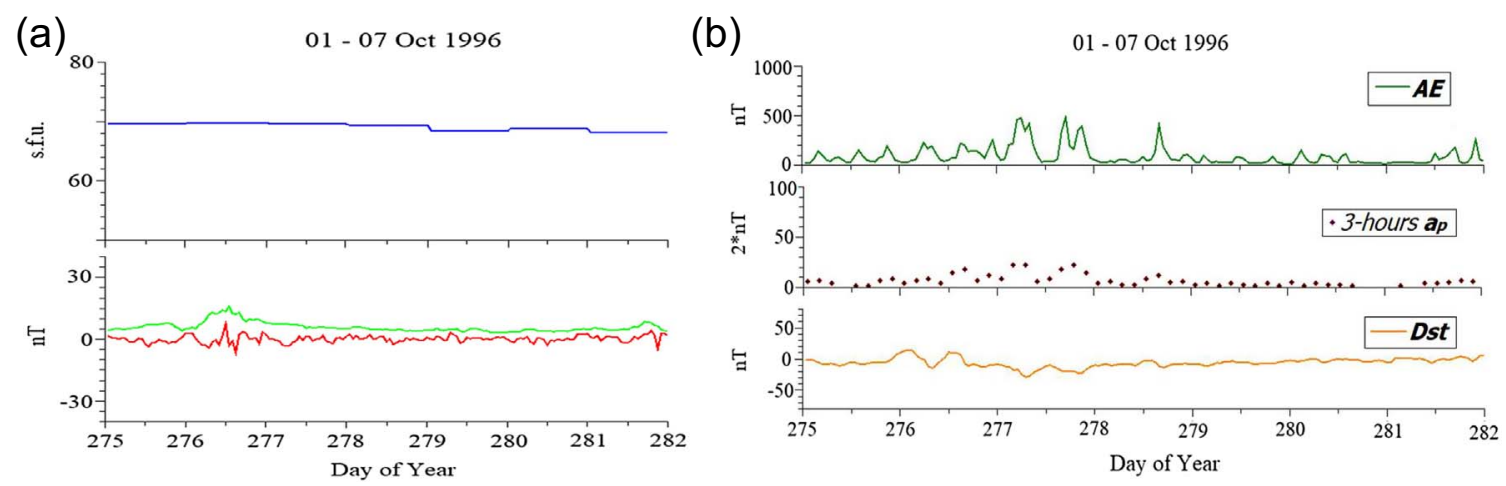

Fig. 10. In panel (a) is described, from up to down, Solar flux F10.7 from 01 to 07 October 1996 and, for the same time period, the behaviour of the magnitude and the $Z$ component of the IMF. Panel (b) shows, from up to down, the $A E$, the $a_{p}$ and the Dst indices, from 01 to 07 October 1996. (The hourly $A E$ index data are retrieved through the Kyoto $A E$ index service http://wdc.kugi.kyoto-u.ac.jp/dstae/index.html. Three-hour $a_{p}$ data are provided by NOAA ftp://ftp.ngdc.noaa.gov/STP/GEOMAGNETIC_DATA/INDICES/KP_AP. Dst and Solar data are obtained from NASA Goddard Space Physics Data Facilities OMNIWEB: https://omniweb.gsfc.nasa.gov/form/dx1.html).
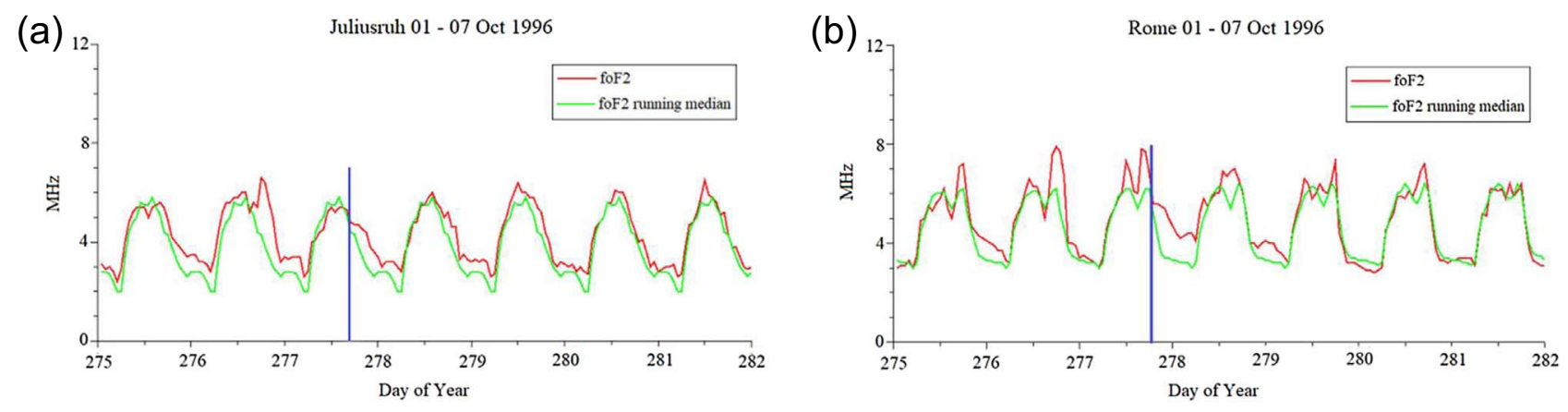

(c)

$01-07$ Oct 1996

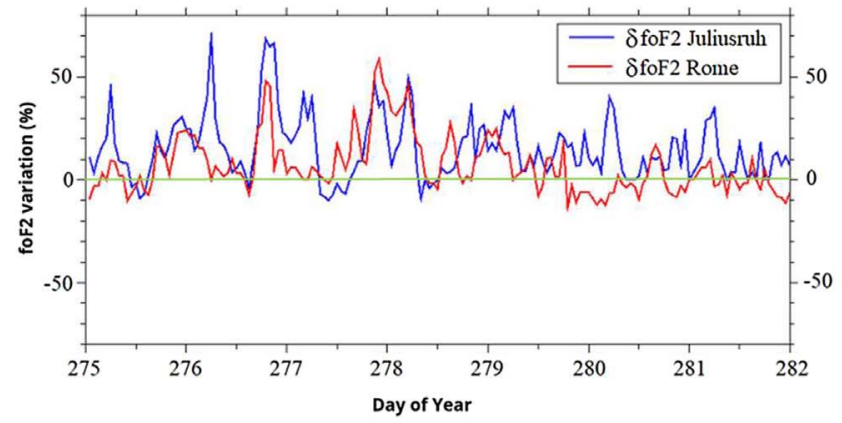

Fig. 11. In panel (a), the red line represents the hourly values of foF2, recorded at Juliusruh ionospheric station from 01 to 07 October 1996. The green line represents the foF2 running median here considered as background value of the ionospheric parameter. In panel (b) the same parameters, recorded by the Rome ionospheric station, are reported, considering the same time period. In panel (c) is reported the variation in percentage of the foF 2 for the two ionospheric stations, for the considered period.

(a) a positive foF 2 variation during day-time hours which is kept until the sunset hours and therefore the night-time foF2 variation starts from high foF2 sunset value (the NmF2 night-time e-fold time is very large);

(b) a plasma influx from the plasmasphere, due to plasma compression under the westward electric field (Mikhailov \& Forster, 1999).

The undertaken analysis based on the foF 2 data registered at the mid latitude Ionospheric Observatory of Rome (Latitude
$41.8 \mathrm{~N}$; Longitude $12.5 \mathrm{E}$ ) during the minima of solar activity at the turn of solar cycles 21-22, 22-23 and 23-24, has revealed 1040 anomalies. Such anomalies, identified as strong deviations of the hourly foF 2 values from the 27-day running median, are characterised by 656 positive and 348 negative variations, with different morphology. The number of positive and negative disturbances we identified in the current paper depends on the median level used to compute the deviation of the hourly foF2 values. Under solar minimum conditions, this is of high relevance: the small number of negative disturbances in the 
critical frequency of the F2 layer, during deep solar minima (i.e. 2007-2009), may just reflect the low median level of the considered ionospheric parameter. Since a big part of the foF2 values used to construct the background is observed in periods of low F10.7 solar fluxes and low $a_{p}$, the frequent appearance of events with positive deviations is more likely. Our findings confirm the results presented by Mikhailov \& Perrone (2018), in their study on the observed June monthly median foF1, retrieved by the total EUV solar flux with $\lambda \leq 1050 \AA$ for the (1946-2015) period. Mikhailov \& Perrone (2015, 2018) showed that the deep and widely discussed solar minimum of 2008/2009 was actually the lowest among the last six solar cycles minima, also in terms of EUV fluxes. The extremely low number of foF2 anomalies in the time period 2008-2009, identified in this work, together with the yearly solar index and $a_{p}$ index information, confirm the existence of an indeed very low minimum (see Table 1). Besides, no strong geomagnetic disturbances, which could cause a decrease in the $\mathrm{NmF} 2$, have been recorded during this deep solar minimum. This might be the explanation for the lack of day time negative foF2 disturbances in 2008 and 2009.

Furthermore, from our study, we observed how, during the solar minimum periods analysed, the number of foF 2 positive anomalies, detected at mid latitude by the Rome ionospheric station, is significantly larger than the number of negative ones. This tendency is even more evident for the last analysed minimum, 2007-2009, where the total number of observed anomalies in the critical frequency foF2, is relatively low.

The study of the two Type II positive storms, occurring on 13 July 1985 and 7 November 1997, confirms the existing formation mechanism (Prölss, 1995, 2004): after the geomagnetic storm onset a TAD is generated due to auroral heating, moving equatorward. The disturbed equatorward circulation transfers, together with the perturbed neutral composition with low $\mathrm{O} / \mathrm{N}_{2}$ ratio at middle latitudes, result in a negative phase of the storm. This means that the first positive phase of this two-step disturbance, is strongly related to the equatorward wind, and daytime positive storm effects are due to TAD moving at the front of this wind surge. The investigation conducted on the two positive foF 2 disturbances of type I, reveals the existence of a different and more complex mechanism. The first analysed strong positive foF2 storm takes place on 16 December 1987, starting during day hours, and lasting for part of the following night. Whereas the activation mechanism of the storm is similar to the one of Type II storms, we identify the following observational fact: while in Juliusruh a negative phase of the storm is evident, at Rome no negative phase takes place. According to the well established Prölss phenomenological model (Prölss 1993, 1995) the occurrence and the sequence of positive and negative ionospheric storm effects depend strongly on the latitude of the observation point and its local time at the geomagnetic storm onset. Based on this dependence, a specific ionospheric location may experience only positive, only negative or a combination of positive and negative storm effects for storm events initiated in different local time sectors. Indeed, we observed that the onset of the storm event in July 1985 (Type II) occurred when Juliusruh and Rome were in the prenoon sector, while the onset of the storm event in December 1987 (Type I) occurred when Juliusruh and Rome were in the morning sector. In this case, the detected differences in the ionospheric response may be related to the local time dependence, which also supports the hypothesis of the impact of TAD in the middle latitudes at specific local time sectors as background mechanisms. The second case study, recorded by the Rome observatory, on 3rd October 1986, cannot be clearly assigned to any geomagnetic activity effect. This Type I ionospheric disturbance is characterised by a positive enhancements in the foF 2 frequency, observed during a period of several days previous and next to the considered event both by Juliusruh and Rome ionosondes, during evening and nighttime hours. Although the $a_{p}$ index is classified in the $G O$ level and no particular variation in the Dst index is recorded, an intense auroral activity is highlighted by the $A E$ index, causing disturbed geomagnetic conditions and consequently ionospheric perturbations. Such increasing in the foF2 observed during nighttime, could be also related to a plasmasphere plasma influx in the F2-region: an electric field, originated in the magnetosphere, drives the plasma from the higher shell to the lower shell. This produce a compression of the plasma in the ionosphere, which turns into a strong enhancement in the electron density at mid latitudes.

\section{Conclusions}

In accordance with the results presented in previous papers (Cander \& Mihajlovic, 1998; Tsagouri et al., 2000), a strong dependence has been observed between foF2 strong disturbances, and perturbed geomagnetic conditions. However, in our work, we find that positive Type I ionospheric disturbances can be observed also during quiet geomagnetic condition, as illustrated for the 3rd October 1996 ionospheric storm. A further interesting feature we found is that, at mid latitudes, positive enhancements in the critical frequency foF2, are mostly observed during low or moderate geomagnetic activity, with apparently no dependence on the time of the day.

The obtained results can be summarised as follows:

1. The study of ionospheric storms during years of low solar activity, allow us to construct a reliable background level of the parameter foF2, suitable for space weather applications, such as the foF2 Alert, under development at INGV and soon available on the ESWA-INGV web portal.

2. The 1040 foF2 anomalies observed at Rome latitude, during the minimum of solar activity of the last three solar cycles, consist in 656 positive ionospheric storms and 348 negative ones.

3. The comparison of the numbers and percentages of the detected anomalies in the critical frequency of the F2 layer, put in evidence the peculiarities of the last deep solar minimum, which is characterized by very few ionospheric anomalies and, among them, negative disturbances have been observed only during night hours.

4. The foF2 anomalies observed by the Rome ionospheric station, confirmed the existence of two types of positive F2 layer disturbances, with different morphology and physical mechanisms.

5. Type I positive perturbations are referred to those followed by quiet ionospheric conditions while positive disturbances of Type II are followed by negative storm. The disturbances of Type I, in which positive ionospheric storms 
are followed by a recovery phase or by a slight positive enhancement in the foF2, occur during low or moderate geomagnetic activity at any time of the day, and are more frequent recorded during night-hours (19-06 LT), while Type II ionospheric storms are more often observed during daytime. The duration of Type II perturbations is shorter than Type I ones, but characterised by a larger amplitude (Zevakina \& Kiseleva, 1978). Negative ionospheric storms are generally preceded by a positive enhancement in the foF2. They occur as a consequence of strong geomagnetic disturbances, especially during night-time and in summer/equinox season.

Acknowledgements. Part of this work has been conducted in the framework of LIMADOU-Science project funded by ASI, and e-SAFE project funded by ESA. Acknowledgements to the following data providers:

INGV-ESWA for foF2 Rome ionosonde data, http://www. eswua.ingv.it/index.php/hf-systems/hf-tools/hf-parametersexplorer

SWS for foF2 Juliusruh ionosonde data, http://www.sws. bom.gov.au/World_Data_Centre/1/3

Kyoto World Data Center for Geomagnetism for $A E$ data, http://wdc.kugi.kyoto-u.ac.jp/dstae/index.html

NOAA for the $a_{p}$ data, ftp://ftp.ngdc.noaa.gov/STP/ GEOMAGNETIC_DATA/INDICES/KP_AP

NASA Omniweb Data Explorer for solar data and Dst data, https://omniweb.gsfc.nasa.gov/form/dx1.html

The editor thanks three anonymous referees for their assistance in evaluating this paper.

\section{References}

Alfonsi L, De Franceschi G, Perrone L. 2001. Long term trend in the high latitude ionosphere. Phys Chem Earth 26(5): 303-307. https://doi.org/10.1016/S1464-1917(01)00003-4.

Balan N, Shiokawa K, Otsuka L, Kukuchi T, Lekshmi DV, et al. 2010. A physical mechanism of positive ionospheric storms at low latitudes and midlatitudes. J Geophys Res 115: A02304. https://doi.org/10.1029/2009JA014515.

Basu S, Guhathakurta BK, Basu D. 1975. Ionospheric response to geomagnetic storms at low midlatitudes. Ann Geophys 31: 497-505.

Bauske R, Prölss GW. 1997. Modeling the ionospheric response to traveling atmospheric disturbances. J Geophys Res 102: 1455514562. https://doi.org/10.1029/97JA00941.

Bauske R, Prölss GW. 1998. Numerical simulation of long-duration positive ionospheric storm effects. Adv Space Res 22(1): 117-121. https://doi.org/10.1016/S0273-1177(97)01110-1.

Buonsanto MJ, Witasse OG. 1999. An updated climatology of thermospheric neutral winds and $\mathrm{F}$ region ion drifts above Millstone Hill. J Geophys Res 1(04): 24675-24687. https://doi. org/10.1029/1999JA900345.

Buonsanto MJ. 1999. Ionospheric storms - A review. Space Sci Rev 88: 563-601. https://doi.org/10.1023/A:1005107532631.

Buresova D, Lastovicka J, Hejda P, Bochnicek J. 2014. Ionospheric disturbances under low solar activity conditions. Adv Space Res 54(2): 185-196. https://doi.org/10.1016/j.asr.2014. 04.007.

Bremer J, Laštovčka J, Mikhailov AV, Altadill D, Bencze P, et al. 2009. Climate of the upper atmosphere. Ann Geophys Italy 52: 273-299. https://doi.org/10.4401/ag-4576.
Cander LR, Mihajlovic SJ. 1998. Forecasting ionospheric structure during the great geomagnetic storms. J Geophys Res 103: 391-398. https://doi.org/10.1029/97JA02418.

Cesaroni C, Scotto C, Ippolito A. 2013. An automatic quality factor for Autoscala foF2 values. Adv Space Res 51(12): 2316-2321. https://doi.org/10.1016/j.asr.2013.02.009.

Danilov AD, Lastovicka J. 2001. Effects of geomagnetic storms on the ionosphere and atmosphere. Int J Geom Aeron 3(2): 201-224.

Danilov AD. 2013. Ionospheric F-region response to geomagnetic disturbances. Adv Space Res 52: 343-366. https://doi.org/10.1016/ j.asr.2013.04.019.

David M, Sojka JJ. 2010. Single-day dayside density enhancements over Europe: A survey of a half-century of ionospheric data. J Geophys Res 115: A12311. https://doi.org/1029/2010JA015711.

Essex EA. 1979. The effects of geomagnetic activity on the F2-region of the ionosphere. J Atmos Sol-Terr Phys 41: 951-960. https://doi.org/10.1016/0021-9169(79)90096-5.

Evans JV. 1973. The causes of storm-time increases of the F-layer at mid-latitudes. J Atmos Sol-Terr Phys 35: 593-616. https://doi.org/ 10.1016/0021-9169(73)90191-8.

Fang H, Weng L, Sheng Z. 2012. Variations in the thermosphere and ionosphere response to the 17-20 April 2002 geomagneticstorms. Adv Space Res 49: 1529-1536. https://doi.org/10.1016/j.asr.2012. 02.024 .

Fuller-Rowell TJ, Codrescu MV, Moffett RJ, Quegan S. 1994. Response of the thermosphere and ionosphere to geomagnetic storm. J Geophys Res 99: 3893-3914. https://doi.org/10.1029/ 93JA02015.

Grozov VP, Bubnova TV, Ilyin NV. 2018. Short-term forecast of ionospheric parameters by oblique sounding data. In: Proc. SPIE 10833, 24th International Symposium on Atmospheric and Ocean Optics: Atmospheric Physics. 108339F. https://doi.org/10.1117/ 12.2503943.

Huang C-S, Foster JC, Kelley MC. 2005. Long-duration penetration of the interplanetary electric field to the low-latitude ionosphere during the main phase of magnetic storms. J Geophys Res 110: A11309. https://doi.org/10.1029/2005JA011202.

Ippolito A. 2019. foF2 variations measured by the Rome observatory during solar minimum in the last three solar cycles. Ann Geophys 62(4): GM452. https://doi.org/10.4401/ag-7762.

Ippolito A, Scotto C, Francis M, Settimi A, Cesaroni C. 2015. Automatic interpretation of oblique ionograms. Adv Space Res 55: 1624-1629. https://doi.org/10.1016/j.asr.2014.12.025.

Ippolito A, Scotto C, Sabbagh D, Sgrigna V, Maher P. 2016. A procedure for the reliability improvement of the oblique ionograms automatic scaling algorithm. Radio Sci 51: 454-460. https://doi. org/10.1002/2015RS005919.

Ippolito A, Altadill D, Scotto C, Blanch E. 2018. Oblique Ionograms Automatic Scaling Algorithm OIASA application to the ionograms recorded by Ebro observatory ionosonde. J Space Weather Space Clim 8: A10. https://doi.org/10.1051/swsc/2017042.

Karpachev AT, Beloff N, Carozzi TD, Denisenko PF, Karhunem TJT, et al. 2010. Detection of large scale TIDs associated with the dayside cusp using SuperDARN Data. J Atmos Sol-Terr Phys 72(9-10): 653-661. https://doi.org/10.1016/j.jastp.2010.02.018.

Kil H, Paxton LJ, Pi X, Hairston MR, Zhang Y. 2003. Case study of the 15 July 2000 magnetic storm effects on the ionospheredriver of the positive ionospheric storm in the winter hemisphere. J Geophys Res 108: 1391. https://doi.org/10.1029/ 2002JA009782.

Kutiev I, Muhtarov P. 2001. Modeling of midlatitude F-region response to geomagnetic activity. J Geophys Res 106: 1550115510. https://doi.org/10.1029/2001JA900018. 
Lu G, Goncharenko LP, Richmond AD, Roble RG, Aponte N. 2008. A dayside ionospheric positive storm phase driven by neutral winds. J Geophys Res 113: A08304. https://doi.org/10.1029/2007JA0128935.

Matuura N. 1972. Theoretical models of ionospheric storms. Space Sci Rev 13: 129-189. https://doi.org/10.1007/BF00198166.

Mendillo M, Klobuchar JA. 1975. Investigations of the ionospheric $\mathrm{F}$ region using multistation total electron content observations. J Geophys Res 80: 643-650. https://doi.org/10.1029/ JA080i004p00643.

Mendillo M, Narvaez C. 2009. Ionospheric storms at geophysicallyequivalent sites - Part 1: Storm-time patterns for sub-auroral ionospheres. Ann Geophys 27: 1679-1694. https://doi.org/ 10.5194/angeo-27-1679-2009.

Mikhailov AV, Skoblin MG, Förster M. 1995. Daytime F2-layer positive storm effect at middle and lower latitudes. Ann Geophys 13: 532-540. https://doi.org/10.1007/s00585-995-0532-y.

Mikhailov A, Forster M. 1999. Some F2-layer effects during the January 06-11, 1997 cedar storm period as observed with the Millstone Hill incoherent scatter facility. J Atmos Sol-Terr Phys 61: 249-261. https://doi.org/10.1016/S1364-6826(98)00129-1.

Mikhailov AV, Depueva AK, Leschinskaya TY. 2004. Morphology of quiet time F2-layer disturbances: high and lower latitudes. Int $J$ Geomag Aeronom 5: 1-14. https://doi.org/10.1029/2003GI000058.

Mikhailov AV, Depuev VH, Depueva AH. 2007. Synchronous $\mathrm{NmF} 2$ and NmE daytime variations as a key to the mechanism of quiet-time F2-layer disturbances. Ann Geophys 25: 483-493. https://doi.org/10.5194/angeo-25-483-2007.

Mikhailov AV, Perrone L. 2009. Pre-storm NmF2 enhancements at middle latitudes: delusion or reality? Ann Geophys 27: 1321-1330. https://doi.org/10.5194/angeo-27-1321-2009.

Mikhailov AV, Perrone L, Smirnova N. 2012. Two types of positive disturbances in the daytime mid-latitude F2-layer: morphology and formation mechanisms. J Atmos Sol-Terr Phys 81: 59-75. https://doi.org/10.1016/j.jastp.2012.04.00.

Mikhailov AV, Perrone L. 2014. Comment on "The winter anomaly in the middle-latitude $\mathrm{F}$ region during the solar minimum period observed by the Constellation Observing System for Meteorology, Ionosphere, and Climate" by W.K. Lee, H. Kil, Y.-S. Kwak, Q. Wu, S. Cho, and J.U. Park. J Geophys Res Space Phys 119: 79727978. https://doi.org/10.1029/2010JA015815.

Mikhailov AV, Perrone L. 2015. The annual asymmetry in the F2-layer during deep solar minimum (2008-2009): December anomaly. J Geophys Res 120: 1341-1354. https://doi.org/10.1002/ 2014JA020929.

Mikhailov AV, Perrone L. 2018. Interminimum foF1 differences and their physical interpretation. J Geophys Res 2018: 768-780. https://doi.org/10.1002/2017JA024831.

Obayashi T. 1964. Morphology of storms in the ionosphere. In: Research in Geophysics, vol. 1, Odishaw H (Ed.), MIT Press, Cambridge, MA , pp. 335-366.

Paznukhov VV, Altadill D, Reinisch BW. 2009. Experimental evidence for the role of the neutral wind in the development of ionospheric storms in midlatitudes. J Geophys Res 114: A12319. https://doi.org/10.1029/2009JA014479.

Perrone L, De Franceschi G. 1998. Solar, ionospheric and geomagnetic indices. Ann Geofis 41: 843-855. https://doi.org/10.4401/ag-3824.

Prölss GW, Jung MJ. 1978. Traveling atmospheric disturbances as a possible explanation for daytime positive storm effects of moderate duration at middle latitudes. J Atmos Sol-Terr Phys 40: 1351-1354. https://doi.org/10.1016/0021-9169(78)90088-0.

Prölss GW. 1991. Thermosphere-ionosphere coupling during disturbed conditions. J Geomag Geoelectr 43(Suppl): 537-549. https://doi.org/10.5636/jgg.43.Supplement1_537.

Prölss GW. 1993. Common origin of positive ionospheric storms at middle latitudes and the geomagnetic activity effect at low latitudes. J Geophys Res 98: 5981-5991.

Prölss GW. 1995. Ionospheric F-region storms. In: Handbook of atmospheric electrodynamics, vol. 2, Volland H (Ed.), CRC Press, Boca Raton, pp. 195-248.

Prölss GW. 2004. Physics of the Earth's space environment. Springer-Verlag, Berlin Heidelberg. 513p.

Rishbeth H. 1991. F-region storms and thermospheric dynamics. $J$ Geomag Geoelectr 43: 513-524. https://doi.org/10.5636/jgg.43. Supplement1_513.

Rishbeth H, Heelis RA, Makela JJ, Basu S. 2010. Storming the Bastille: the effect of electric fields on the ionospheric F-layer. Ann Geophys 28: 977-981. https://doi.org/10.5194/angeo-28-977-2010.

Rodger AS, Wrenn GL, Rishbeth H. 1989. Geomagnetic storms in the Antarctic F-region. II. Physical interpretation. J Atmos Sol-Terr Phys 51: 851-866. https://doi.org/10.1016/0021-9169 (89)90002-0.

Scotto C, Pezzopane M. 2002. A software for automatic scaling of foF2 and MUF (3000) F2 from ionograms. URSI XXVIIth General Assembly. https://www.ursi.org/proceedings/procGA02/papers/ p1018.pdf.

Stanisławska I, Zbyszynski Z. 2001. Forecasting of the ionospheric quiet and disturbed f0F2 values at single location. Radio Sci 36: 1065-1071. https://doi.org/10.1029/1999RS002242.

Tsagouri I, Belehaki A, Moraitis G, Mavromichalaki H. 2000. Positive and negative ionospheric disturbances at middle latitudes during geomagnetic storms. Geophys Res Lett 21: 3579-3582. https://doi.org/10.1029/2000GL003743.

Tsagouri I, Belehaki A. 2008. An upgrade of the solar-wind-driven empirical model for the middle latitude ionospheric storm-time response. J Atmos Sol-Terr Phys 70: 2061-2076. https://doi.org/ 10.1016/j.jastp.2008.09.010.

Tsurutani BT, Gonzalez WD. 1995. The future of geomagnetic storm predictions: implications from recent solar and interplanetary observations. J Atmos Sol-Terr Phys 57(12): 1369-1384. https://doi.org/10.1016/0021-9169(95)00138-R.

Wrenn GL, Rodger AS, Rishbeth H. 1987. Geomagnetic storms in the Antarctic F-region. I. Diurnal and seasonal patterns for main phase effects. J Atmos Sol-Terr Phys 49: 901-913. https://doi.org/ 10.1016/0021-9169(87)90004-3.

Yao Y, Liu L, Kong J, Zhai C. 2016. Analysis of the global ionospheric disturbances of the March 2015 great storm. J Geophys Res Space Phys 121: 12157-12170. https://doi.org/10.1002/ 2016JA023352.

Zevakina RA. 1971. Ionospheric disturbances. In: Ionospheric disturbances and their impact on radio communication, Nauka, Moscow, pp. 3-26 (in Russian).

Zevakina RA, Kiseleva MV. 1978. F2-region parameter variations during positive disturbances related to phenomena in the magnetosphere and interplanetary medium. In: The diagnostics and modelling of the ionospheric disturbances, Nauka, Moscow, pp. 151-167 (in Russian).

Cite this article as: Ippolito A, Perrone L, Plainaki C \& Cesaroni C 2020. Investigating the foF2 variations at the Ionospheric Observatory of Rome during different solar cycles minimums and levels of geomagnetic activity. J. Space Weather Space Clim. 10, 52. https://doi.org/ 10.1051/swsc/2020054. 